\title{
Value Chains vs. Ecosystems: Current Perspectives Among Swedish SMEs Entering the Interconnected World of IoT
}

\author{
Victor CENTERHOLT ${ }^{\mathrm{a} 1}$ Frida KJIDDERÖ ${ }^{\mathrm{b}}$ Ted SAARIKKO $^{\mathrm{c}, \mathrm{d}}$, Sten GRAHN ${ }^{\mathrm{a}, \mathrm{e}}$ \\ ${ }^{a}$ Research Institutes of Sweden, \\ Dept Product Realization Methodology, Stockholm, Sweden. \\ ${ }^{b} A K O A$, \\ Göteborg, Sweden. \\ ${ }^{c}$ Umeå University, \\ Dept of Informatics, Umeå University,Umeå, Sweden. \\ ${ }^{d}$ Swedish Center for Digital Innovation, \\ Dept of Informatics, Umeå University, Umeå, Sweden. \\ e Mälardalen University, \\ Div Product Realisation, Eskilstuna, Sweden.
}

\begin{abstract}
Smart connected industrial products and the Internet of Things (IoT) are transforming the industrial business landscape in a radical way. To reach the full potential of IoT-technologies manufacturing firms are forced to rethink almost every aspect of their value creation process. To utilize this promising digital technology and to cope with the new market conditions of IoT environments, research shows that industrial firms have to make a fundamental shift in value creation logic and break free from the value chain perspective of business. Instead they have to embrace a view where value is co-created within ecosystems in both a vertical and a horizontal manner. By exploring the value creation logic of small and medium sized (SME) Swedish industrial machinery manufacturers, this study contributes to a deeper understanding of how manufacturing firms view their value creation processes and how aligned this logic is to the latest research in IoT. The study found that Swedish industrial machine manufacturers do understand the transformative force of IoT-technologies and see great business opportunities to utilize IoT in their business. The study, however, identified a lack of co-creation and difficulties in embracing an ecosystem perspective. While quick to embrace change on a technical level, respondents still adhere to a firm-centric and linear perspective of value creation, with a strong attachment to the value chain concept. The study suggests that it is not a lack of technical proficiency or engineering know-how, but rather an adherence to goods-dominant logic and attachment to the value chain concept that prevent Swedish SME manufacturers from fully embracing the growing market of industrial IoT. Hence, we see an urgent need for both practitioners and academia to shift their attention from the dazzling potential of cutting-edge technologies to the nitty-gritty business of incorporating co-creation and ecosystem-thinking into current business practices.
\end{abstract}

Keywords: Internet of Things, Value Creation, Dominant Logic, Small and Medium-sized Enterprises, Qualitative Study

\footnotetext{
${ }^{1}$ Corresponding author. victor.centerholt@ri.se
} 


\section{Introduction}

The development of digital technologies embedded in industrial products has created the phenomena of interconnected and communicating machines and devices called the Industrial Internet of Things (IoT). The usage of IoT has seen massive growth and brings new rules to the competitive business landscape of manufacturing. Ericsson [1] forecasted that there will be 1.5 billion IoT devices with cellular connections by 2022 and Accenture [2] estimated that the Industrial IoT could add 14.2 trillion dollars to the global economy by 2030. The concept of IoT is often referred to as a new technological paradigm and a radical transformative force that could have a significant impact on several industries [3] [4].

However, despite the rapid growth of IoT and the new opportunities this technological paradigm brings, scientific and practical understanding of this phenomena is still in the initial stages [5]. One of the key challenges is understanding the disruptive effects that IoT has in the industrial business landscape by changing the fundamental nature of products, value chains and industry structures [4]. IoT brings a new digital and network-based competitive business landscape where actors are part of a bigger and more dynamic system of many collaborative actors, working together to optimize the overall performance of an offer for the customer [4]. In line with this notion, recent research indicate that the adoption of an "ecosystem" strategy by IoT-firms encourages collaborations with outside partners for the co-creation of value for customers; a transition that is described as quite challenging to overcome for traditional manufacturing firms [6].

Previous research has highlighted that during technological paradigm shifts, organizations need to both develop new technical capabilities as well as adapt to new strategic beliefs based on new structures of the competitive landscape [7]. Recent research has highlighted the importance of changing strategic beliefs to stay competitive in IoT-environments [8]. The attachment to existing norms, value chains, and business models inhibit of proper exploration of the true promise of IoT. Furthermore, to cope with the new ecosystem structures of the digital age, recent literature has highlighted understanding of the value creation process (the dominant logic of value creation) as a cornerstone of the new strategic beliefs that have to be adopted to prosper in a digital age [9] [10]. Accordingly, digitalization alters our perspective on value creation by emphasizing value as something that is co-created by multiple actors in networks [9] [10].

In the shift towards adopting IoT within the manufacturing industry (also referred to as Industry 4.0), the Swedish government has presented a strategy to become the world leader. The strategy furthermore stresses the importance of supporting and strengthening the small and medium sized (SME) industrial firms' ability to utilize digital technologies to enhance their competitiveness [11]. Recent reports from the Swedish agency for innovation (Vinnova) show that Swedish industrial firms struggle to incorporate and capitalize on digital technologies in their business offerings. This is a somewhat unexplored topic, as a report from the Swedish agency for innovation highlights that there is not enough research that addresses the effect of this kind of technology on the business industrial firms in a Swedish context [12].

As a response to the growing usage of IoT within Swedish industrial firms, in combination with the limited research focusing on basic key business issues within this field, the purpose of this paper is to explore how small and medium sized Swedish manufacturing firms understand and analyze value creation. There is a need to extend 
the understanding tied to the dominant logic of value co-creation and ecosystem strategy that is needed in IoT environments. Hence, the presented in this paper was guided by the following question: How does the current dominant logic among SME manufacturers affect their value creation efforts in relation to IoT?

\section{Theoretical background}

\subsection{The Internet of Things}

IoT consists of smart and connected products that utilize sensors, connectivity and software to attain information such as usage and condition, which could be used to improve output, utilization and efficiency of products and systems [3] [4] [5]. IoT in an industrial context, such as a factory, is referred to as the Industrial Internet of Things (IIoT); a concept that is based on the same principles as IoT but has its focus on connectivity and communication between industrial machines and systems [13]. IIoT is referred to as a system of networked smart objects within an industrial environment, that enables intelligentfunctions through collection, analysis and communication of information, to optimize overall production value [14]. IoT has further been referred to as one of the drivers for industry 4.0 and as a core technology for the smart factory [15] [16].

\subsection{Value Creation in IoT Environments}

In the traditional linear view of value creation, the firm is the sole actor in the process of creating and delivering value [17]. Previous research has stressed that due to a more digitalized and network-dependent business landscape, it is of great importance to move away from an outdated value chain perspective (particularly used in manufacturing) of competitive environments and instead embrace a perspective more suitable for the digital economy, where value is co-created in networks [18]. Several scholars have pointed out the importance for industrial firms to adopt an ecosystem and co-creation perspective to succeed and prosper in an IoT business landscape [19] [20]. From a business perspective, the utilization of IoT opens up possibilities for industrial firms to develop innovate business models based on new value propositions, i.e. how a new product or system can under the right circumstances create value, and new income streams. This could further spur incentives for manufacturing firms to rethink and redesign their products and business models to stay relevant in the digital market [13].

Ghanbari et al. [20] describe that the potential of IoT lies in the interaction and the co-creation of value among multiple actors. They further argue that firms need to reevaluate business models that are based on the single firm generating value and accept the new rules of the network-centric IoT market. To succeed in IoT environments, firms have to adopt to the complex ecosystem setting of both vertical and horizontal cocreation business interactions. Vertical interactions closely resemble traditional business relationships such as between retailer and customer. Horizontal interactions consist of relationships with similar firms in the surrounding value creation environment of the customer. This could be other firms that provide similar offerings and solutions and usually involve some level of competition. Identifying and attempting to capitalize on these vertical and horizontal business interactions could be challenging for a company 
as they may interfere with existing mutually beneficial agreements among other stakeholders within the IoT ecosystem.

The nature of value creation that technologies such as IoT bring has raised the question for a new suitable perspective on which to base the development of strategies and business models [5] [9]. Several scholars have argued for applying a service dominant logic (S-D logic) perspective as a foundational logic for understanding value creation in an era of IoT. Based on its value co-creation and ecosystem-centred view, Turber et al. [21] propose that the S-D logic concept is the right perspective on which to develop a suitable business model for IoT. This perspective, supported by Lai et al. [22], argues that shifting towards an S-D logic mindset could provide a suitable perspective for IoT by steering strategies and investments towards a necessary co-creation and ecosystem perspective. This view is also supported by $\mathrm{Ng}$ and Wakenshaw [23] who argue that the S-D logic provides a framework that enhances our understanding of the interplay between different institutions, individuals and other entities in the IoT ecosystem.

\subsection{Dominant Logic}

Prahalad and Bettis [24] define dominant logic as a cognitive map that affects our world view and our problem-solving behavior. Therefore, dominant logic has a strong impact on the organization processes to accomplish goals and make strategic business decisions. This view could have a useful function in established firms when it comes to incremental innovation processes in business and technological environments that are familiar to the firm [25]. On the other hand, this cognitive map can become too nearsighted and dysfunctional when the firm is exposed to unfamiliar environments such as when they are facing a new emerging technology. The prevailing mindset of previous success formulas and conventional wisdom could prevent the organization from adapting to a new logic. Radical technological changes not only require development of new technological capabilities, but also adoption of new strategic beliefs that reflect the world view of their management [7].

Previous research on adoption of digital technologies provides important insights in how dominant logic causes tensions between digital visions and business practices in incumbent manufacturing firms [26]. As incumbent manufacturing firms expand their businesses by incorporating digital technology, they also have to incorporate non-linear forms of value creation in order to fully realize the benefits and potential of their investments [26]. As previously mentioned, proper exploration of the true promise of IoT is inhibit by the attachment of existing norms, value chains and business models [5]. Therefore, the adoption of a new dominant logic could be crucial for the long-term health and survival of a firm that faces disruptive changes in their business environment - such as the introduction of IoT.

\subsection{Goods and Service Dominant Logic}

Vargo and Lusch [27] divide the view of value creation in two different dominant logics, the goods dominant logic (G-D logic) and the service dominant logic (S-D logic).

G-D logic is a worldview that is characterized by a firm-centric approach that holds a linear-view of value-creation at its core [27]. This view on value creation has been referred to by other scholars as "manufacturing logic" [28] or as "firm-centric" logic [29]. G-D logic views goods as value-laden, and its view of value creation could be 
derived from the value chain concept which emphasizes the internal value adding activities of the firm. In this view, the purpose of all economic activity is to produce and sell goods that are imbued with value. The value that goods possesses comes from the production process of goods, a process which consists of value-adding activities [27]. Lusch and Nambisan [9] describe the value-adding process as "[..] transforming matter to change its form, time, place, and possession. Predictably, these transformations require costs, which are often labeled as 'value added' and a source of utility" [p. 159]. In the firm-centric and linear value creation process of the G-D logic, the firm takes the role of defining, creating and controlling actors and is the epicenter of the value creation process [27].

S-D logic is an institutional logic of value creation that challenges the established G-D logic. Vargo and Lusch [27] [30] argue that the traditional, firm-centric and linear view of value creation process possesses underlying assumptions that have shortcomings due to the perspective of exchange of tangible goods. The S-D logic of value creation is based on a radically different perspective than the G-D logic view. At the core of the S$\mathrm{D}$ logic framework is the concept of value co-creation [27] [31]. Co-creation is defined as the process of merging a range of resources for the purpose of creating new resources with value potential [30]. In contrast to the linear view of G-D logic, S-D logic embraces a more systemic network-oriented perspective of value creation, where the co-creation of value is performed by multiple actors in an interwoven fabric of individuals and organizations engaging in a collaborative process of value co-creation by the integration of resources [32]. S-D logic further uses the term "service ecosystem" to characterize the ever changing and dynamic systems of participating actors in the value co-creation process [30] [31].

\section{Research Method}

\subsection{Research desgin}

This explorative qualitative study was performed through in-depth interviews with Swedish industrial automation firms as the primary data source. The focal point of this study was the Swedish Industrial Automation manufacturing industry.

The authors interviewed representatives from 19 companies. This number achieved data saturation, assuming that minimal additional information was gained by every new interview and thus the retrieved data collection provided sufficient information to achieve generalizability [33]. The interviews with each representative were recorded and later transcribed for analysis.

The following criteria outlined the judgment of suitability when choosing respondents:

1. The company was Swedish manufacutrer of industrial automation equipment;

2. The company was considered an SME according to the chosen definition from the EU;

3. The interview respondents were from functions in the company with insight into strategic matters.

The interviews were semi-structured in order for the respondents to be able to openly share and explain their insights and knowledge [34]. The interviews followed an 
interview-guide that was inspired by the questions from Bettencourt, Lusch and Vargo [35] in their guidance of application questions tied to companies' value creation and strategic advantage.

Table 1: Respondents

\begin{tabular}{|c|c|c|c|c|}
\hline Company & Industry & Employees & Turnover 2018 & Respondent Title \\
\hline HeatingCorp 1 & Gas Heating Equipment & 9 & 15, 9 MSEK & $\begin{array}{l}\text { Business } \\
\text { Development } \\
\text { Director }\end{array}$ \\
\hline RoboCorp 1 & $\begin{array}{l}\text { Automation Tools } \\
\text { Manufacturer }\end{array}$ & 6 & 7, 8 MSEK & Founder and CEO \\
\hline RoboCorp 2 & $\begin{array}{c}\text { Automation Tools } \\
\text { Manufacturer }\end{array}$ & 80 & 150, 2 MSEK & CEO \\
\hline OvenCorp 1 & $\begin{array}{l}\text { Oven Manufacturer, } \\
\text { Service and Spare Parts } \\
\text { Seller }\end{array}$ & 25 & 72 MSEK & $\mathrm{CEO}$ \\
\hline DryCorp & Drying Equipment & 10 & 10 MSEK & CEO \\
\hline AirCorp & $\begin{array}{l}\text { Air Purification } \\
\text { Equipment }\end{array}$ & 216 & $491 \mathrm{MSEK}$ & CEO \\
\hline WashCorp & $\begin{array}{l}\text { Manufacturing Parts and } \\
\text { Washing Machine }\end{array}$ & 35 & $60 \mathrm{MSEK}$ & CEO and Owner \\
\hline Bevelling Corp & Beveling Machine Tool & 6 & 375000 MSEK & Local Manager \\
\hline ElevatorCorp & Vertical Storage Lift & 44 & 130 MSEK & CEO \\
\hline OvenCorp 2 & $\begin{array}{l}\text { Oven and Heating } \\
\text { Equipment }\end{array}$ & 35 & $50 \mathrm{MSEK}$ & Part Owner \\
\hline PackingCorp & Packaging Machines & 35 & $50 \mathrm{MSEK}$ & $\mathrm{CEO}$ \\
\hline SewingCorp & Sewing Machines & 32 & $55 \mathrm{MSEK}$ & CEO \\
\hline $\begin{array}{l}\text { AutomationElectr } \\
\text { onicsCorp }\end{array}$ & Automation Electronics & 30 & 45 MSEK & $\mathrm{CEO}$ \\
\hline WaldingCorp & Welding Machines & 30 & $70 \mathrm{MSEK}$ & Head of Marketing \\
\hline X-RayCorp & X-Ray Machines & 12 & 9 MSEK & CEO \\
\hline ConveyorCorp & Conveyors & 65 & 155 MSEK & CEO \\
\hline $\begin{array}{l}\text { ProcessMachineC } \\
\text { orp }\end{array}$ & $\begin{array}{l}\text { Machines for the Process } \\
\text { Industry }\end{array}$ & 120 & 220 MSEK & CEO \\
\hline LaserCorp & Laser Systems & 24 & $60 \mathrm{MSEK}$ & CEO \\
\hline LiftCorp & Lifting Systems & 80 & 130 MSEK & $\mathrm{CEO}$ \\
\hline
\end{tabular}

\section{Results}

\subsection{New Business Possibilities through IoT - Transformative Force of IoT}

The interviews indicated that the current business models among most respondents were based on a traditional transaction; selling a machine and then add services for maintenance. However, the result shows that the respondents saw great opportunities to utilize IoT to create new streams of income and explore new business models. The result also shows that the respondents heavily invested in digital technologies, IoT capabilities and upgrades of their technical proficiency and engineering know-how in connectivity 
and IoT. This is, for example, stressed by the CEO of ConveyorCorp who described their investments and needs:

" $80 \%$ of our R\&D cost for products is in developing digital capabilities, and I am convinced that it will stay so." - ConveyorCorp

Several of the respondents argue that IoT enables them to be more predictive in the planing of their operations by collecting status updates from their machines. This capability has further driven the opportunity to change their value propositions from selling machines to selling machine up-time. Another approach was to utilize IoT technology to expand and strengthen current service business of the firm. One of the respondents who saw great opportunities in collecting data when utilizing the IoT products was the CEO of ElevatorCorp, who argued that IoT opened up new ways to serve their customers and new business opportunities.

"We are collecting data that will enable us to offer a sort of 'all-inclusive-deal' on services where we can say to the customer, 'Do what you want and how you want, this is your full price each month'." - ElevatorCorp

The CEO from ProcessMachineCorp described how IoT will have a more disruptive effect on their business model, arguing that IoT use and data collection will enable them to create a whole new value proposition and take a strategically new market position. By collecting data through IoT, ProcessMachineCorp aimed to generate greater understanding of its customers' process to further develop a business model that is outcome- and knowledge-based rather than based on selling physical products to customers.

"I think that in the future, instead of being a hardware-supplier, we will become a supplier of knowledge." - ProcessMachineCorp

"Suddenly we have an understanding of what they are doing in a completely different way. We don't only store information about our machines, but also information on how they use it. Through that information we can become better in helping our retailers in designing their own systems. [..] Suddenly, we went from being a machinesupplier to be their most important partner, if the transformation is successful."ProcessMachineCorp

Results indicates that there was an understanding that IoT will be a transformative force to the manufacturing industry, which will create new possibilities and demands for the respondents [3] [15] [16]. Furthermore, the respondents were eager to utilize the new possibilities that IoT brings to develop new value propositions, transform their business models and gain a greater strategic position in the market [4]. However, among the respondents, there was a strong focus on addressing this technology by heavily investing in upgrades of technical proficiency and engineering know-how. Little or no attention was paid on addressing the need of adoption of new strategic beliefs [7] [25].

\subsection{Current Perspective on Value Creation}

There was a similar view among the respondents of what kind of value the customer is seeking when they purchase industrial machines for production purposes. Several of the respondents described that the focal needs of their customers is to increase productivity, efficiency, quality and capacity in their production system. This view was presented by Aircorp that stated:

"The dynamics [when comparing] between different machinery manufacturers is quite the same. A lot of it is about increasing productivity for your end-customer in some way. You want to help the customer to produce more precisley" - Air-Corp 
In a similar way as the CEO of Air-Corp, the CEO of OvenCorp described the benefit the customer is seeking from their offerings:

"We deliver a sort of productivity to our customers, [...] the customer got the heat treatment of their products that enable them to produce a product for the right price." OvenCorp 1

The majority of the respondents held a firm-centric view of value creation. Among the respondents, there was a perception that the development and assembly of machines created value and that higher value creation could be created by higher internal efficiency in the production process. The respondents described that the most important partners in the value creation process were the partners who supplied the creation of the physical machine, such as the suppliers of electric motors and programmable logic controllers. This view further supports an internal focus on the value creation process and a process that sees value as something that becomes "embedded" into the products during the manufacturing process. This perspective is evident in the case of ElevatorCorp who argues that their competitiveness was based on their internal structural methods and routines to generate greater efficiency and output. Another example of this was offered by ProcessMachinesCorp:

"We keep track of every minute we spend on each product, every gram sheet metal that we consume. This results in great insights on how much each machine costs to produce." - Process MachineCorp

The importance of internal processes for value creation was also evident in the cases of DryCorp, LiftCorp and LaserCorp, where the respondents emphasized the importance of more efficient internal processes to decrease the cost per sold unit which, in turn, had an effect on the value-in-exchange. In LaserCorp, the CEO argued that their short-term focus to create value was by creating a more efficient internal product development process and shortening the engineering hours on each project.

The majority of the respondents reflected a view in line with the concept of value chains, which was how a large part of the respondents described their relations with customers, suppliers and other partners when making strategic choices of how they create value. The result indicates that there was a lack of respondents' acknowledging that the other outside actors were part of creating the desired benefit that they claimed to deliver to the customer.

The respondents often showed a view on efficiency grounded in internal activities as a way to "optimize" value delivery to the customer. This viewpoint is a typical characteristic of the G-D logic [27] [31]. There was a coherent view of value creation as something that can be created internally in the firm and then be delivered to a "value receiver" (the customer) by value laden-goods.

The respondents described a perspective of their value propositions that is aligned with Boyes et al. [14] definition of how the Industrial IoT will boost and optimize production value. However, there was a distinct absence of a co-creation and ecosystem perspective among the respondents. On the contrary, when defending and analyzing the process of value creation, the respondents showed a strong attachment to the linear perspective of value creation and to the concept of value chains. This linear perspective of value creation is in line with the perspective of the traditional manufacturing logic [28] [29] and G-D logic [27] [31]. 


\subsection{The Demand for New Cooperation Structures in IoT-Environments}

Among the respondents, there was a similar view of what the concept of a smart factory meant. The majority of them described a factory with interconnected machines and systems that had the ability to communicate with each other and create a complete view of the ongoing process in the facility. However, the respondents also highlight that this view is far from the current reality of the manufacturing industry. A great number of the respondents described that digital and connected machines and systems exist to a great extent but are working as silos or as isolated "technological islands". During the interviews, several of the respondents highlighted that the digital technical development has made manufacturing processes more complex and that production systems become more integrated with other organizational systems. However, handling the increased digitalization and integration of systems is challenging among the respondents. Many of the respondents witnessed challenges to find technical standards and cooperation models to work together with other machine suppliers to achieve the seamless integration among different digital and machine systems within the production system.

The respondent from Aircorp argued that there is a great interest for IoT solutions among their customers and there were machines with technical IoT capabilities, but that they had never seen a full-scale IoT implementation among their customers (some of the biggest manufacturing firms in the world). The respondent from AirCorp argues that machine manufacturers do not pay attention to the need for machines to have the capability to collaborate with other actors in IoT environments, which results in machines and technologies working in isolation rather than in a collaborative way. This way of thinking is comparable with a firm-centric value creation perspective, which does not acknowledge other actors in the IoT environment as co-creators of value.

"There are isolated islands in the production and the question is if someone will eventually develop the system that connects all these machines together. Today, everyone is connected, but individually. We work with our systems; they work with theirs. If I were a customer, I would not want it that way. I would want to have one system to rule the other systems." - AirCorp

A great number of the respondents also highlighted that the technical development has increased the complexity of production systems to a degree where the customers find it hard to handle and have knowledge of all the different systems that is of importance for their manufacturing operations. The customers are increasingly demanding new purchasing processes that decrease this complexity by reducing the number of actors they choose to work with. This demand has forced machine manufacturers to open up new ways to collaborate with each other for the purpose to make it less complex for their customers and still be able to focus on their core competence in the production system.

"The manufacturing process just gets more and more complex. You cannot do everything by yourself and you have to open up new ways of collaborating with other actors to be able to deliver a good solution to the customer." - SewingCorp

The increased complexity in production systems has raised the awareness of the need of new vertical and holistic partnership constellations. However, even though there was an awareness, the respondents highlighted insecurity regarding how to engage in and structure the holistic partnerships that are needed. This insecurity was among other things rooted in the fear of being exploited by competitors. This tension in new partnership constellations was highlighted by the respondent from Automation-ElectronicsCorp as:

"It is hard to get all the actors together because you never work with open books or strategies." 
Aligned with research from Akram et al. [26], the current traditional linear thinking of value creation is creating tensions regarding how to handle the new vertical and horizontal cooperation structures that IoT requires. The inability to cooperate with actors horizontally could become a serious business disadvantage in IoT-environments [19] [20]. Breaking free from the value chain mindset and embracing an ecosystem view of value creation could enable a better prerequisite for handling these new horizontal business interactions that the respondents face when entering interconnected IoTenvironments [20] [26].

\section{Discussion, conclusions and further research}

The purpose of this paper has been to generate understanding on small and medium sized Swedish manufacturing firms understand and analyze value creation and how this reflects the need of a co-creation and ecosystem thinking in IoT-environments such as a smart factory.

Based on existing literature on the topic of business development and value creation in IoT-environments, we draw the conclusion that IoT business environments require participating actors to have a co-creation and network-centric perspective on value creation [19] [20]. A mindset that is unconventional in the traditional manufacturing industry [26]. As highlighted by Tripsas and Gavetti [7], new technological paradigms require adoption of new technical capabilities and new strategic beliefs that are grounded in a suitable dominant logic for the new competitive business landscape. However, the result shows that the respondents are investing in and upgrading their technical capabilities but are still holding on to a linear, firm-centric, G-D logic world view of value creation [27].

The result indicates a strong attachment to the value chain process which could prevent firms from maximizing the benefits from their investments [5]. Under such circumstances, entering an IoT environment while holding on to a traditional G-D logic view of value creation, manufacturing firms such as producers of industrial machines could become limited in their digital value creation abilities [5] [26]. This logic can hold manufacturing firms back in their digital transformation and prevent them from taking part in a growing Industrial IoT business landscape that is dependent on co-creation of value in ecosystem structures. To escape the trajectory of building IoT strategies and business models upon an inappropriate value creation logic of G-D logic, we argue that there is a great need to shift to a more suitable value creation logic to unlock the true business potential of IoT.

We believe that shifting towards a dominant logic suitable for industry 4.0 should be seen as a foundational part of a firm's digital transformation process. We further argue that this shift in logic is inherently important for the the manufacutring industry as a whole to be able to utilize the potential value that IoT could bring. This should also be a priority for the Swedish government, having ambitions of being a world leader in utilizing digital technology. This shift will be crucial of staying competitive as an industrial and innovative nation. Since the very beginning, S-D logic has emphasized that value is created in use (value-in-use) and resources have to be in a useful state for the beneficiary to create actual usefulness [27]. We argue that value-in-use also applies to theoretical models for value creation and business strategy.

Due to its emphasis on co-creation and ecosystem, we agree with previous research that S-D logic could be a suitable framework for value creation derived from IoT [8] [21] 
[23]. We share the view of $\mathrm{Ng}$ and Wakenshaw [23] that S-D logic could provide a framework that enhances the understanding of the interplay between different institutions, individuals and other entities in IoT systems.

We further purpose that S-D logic could be used as a heuristic perspective for guidance and demarcation of strategy and resource allocation for IoT implementation. However, we also see that S-D logic is not yet mature enough to be used as a concrete framework for leading IoT business transformation in small and medium sized industrial firms. This issue of practical use has already been addressed by Vargo and Lusch [36] who stress the fact that being useful beyond a meta-theoretical S-D logic requires developing more midrange theoretical frameworks as well as evidence based research. We therefore see a need for further research, both conceptual and empirically grounded, with the explicit purpose to develop theoretical frameworks for adoption and implemetation of connected equipment rooted in SD-logic.

\section{References}

[1] Ericsson, (n.d.), Ericsson, Mobility Reports, Acssesed: 15.05.2019 [Online]. Avaiable: https://www.ericsson.com/en/mobility-report/internet-of-things-forecast

[2] Accenture, 2015, Winning with the Industrial Internet of Things: How to accelerate the journey to productivity and growth. Acssesed: 15.05.2019.[Online]. Avaiable https:/www.accenture.com/usen/ /media/accenture/conversion-assets/dotcom/documents/global/pdf/digital_1/accenture-industrialinternet-of-things-positioning-paper-report-2015.pdf

[3] I. Lee, and K. Lee, The Internet of Things (IoT): applications, investments, and challenges for enterprises. Business Horizons, vol. 58, pp. 431-440, 2015.

[4] M. Porter, and J. Heppelmann,.How Smart, Connected Products Are Transforming Competition. Harvard Business Review , vol.. 92, pp. 64-88, 2014.

[5] T, Saarikko, U.-H Westergren, T. Blomquist. The Internet of Things: Are you ready for what's coming? Business Horizons, vol. 60 (5), pp. 667-676, 2017.

[6] V. Centerholt, S. Mattsson and F. Rälg. From egosystem to ecosystem: how a 150-year old manufacturing firm is taking on the world of Internet of Things, Procedia Manufacturing, vol. 38, pp. 471-477, 2019.

[7] M. Tripsas and G. Gavetti. Capabilities, cognition, and inertia: Evidence from digital imaging. Strategic Management Journal, vol. 21 (10-11), pp. 1147-1161, 2000.

[8] C.-T. Lai, P.-R. Jackson and W. Jiang, Shifting paradigm to service-dominant logic via Internet-of-Things with applications in the elevators industry, Journal of Management Analytics, vol.4 (1), pp. 35-54, 2016.

[9] R.-F. Lush and S. Nambisan, Service innovation: A Service-Dominant Logic Perspective. MIS Quarterly. vol.39 (1), pp. 155-176, 2015.

[10] P. Hukal, and O. Henfridsson, Digital innovation - A definition and integrated perspective, The Routhlege Companion to Management Information Systems, 2017

[11] The Ministry of Enterprise and Innovation in Sweden, 2016, Smart industri - en nyindustrialiseringsstrategi för Sverige, Acssesed: 15.05.2019 [Online]. Avaiable: https://www.regeringen.se/conten-tassets/869c75f458fc4585ab4ec8c13b250a07/informationsmaterialsmart-indus-tri---en-nyindustrialiseringsstrategi-for-sverige

[12] Vinnova, 2018, Digitalisering - mer än teknik kartläggning av svensk forskning och näringslivets behov, Acssesed: 15.05.2019 [Online]. Avaiable: https:/www.vinnova.se/publikationer/digitalisering--mer-anteknik/

[13] S. Gierej. The Framework of Business Model in the Context of Industiral Internet of Things, Procedia Engieenering, vol. 182, pp. 206-212, 2017.

[14] H. Boyes ,B. Hallaq, J. Cunningham and T. Watson, The industrial internet of things (IIoT): An analysis framework, Computers in Indusry, Vol.101, pp. 1-12, 2018.

[15] S.Wang, J.Wan, D. Li, and C. Zhang, Implementing smart factory of industrie 4.0: an outlook, International Journal of Distributed Sensor Networks, vol 7, pp. 1-10 . 2016

[16] D.-R. Sjödin, V. Parida, M. Leksell, and A. Petrovic, Smart Factory Implementation and Process Innovation. Research-Technology Management, vol. 61 (5), pp. 22-31, 2018

[17] M. Porter, Competitive Advantage: Creating and Sustaining Superior Performance. New York: Collier Macmillan. 1985. 
[18] J. Peppard and A. Reylander, From Value Chain to Value Network: Insights for Mobile Operators, European Management Journal, vol. 24, pp. 128-141, 2006

[19] M. Westerlund, S. Leminen, and M. Rajahonka, Designing Business Models for the Internet of Things, Technology Innovation Management Review, vol. 4, pp.5-14, 2014.

[20] A. Ghanbari, A. Laya, J. Alonso-Zarate, and J. Markendahl, (2017). Business development in the Internet of Things: A matter of vertical cooperation, IEEE Communications Magazine, vol. 55, no. 2, pp. $135-141,2017$.

[21] S.Turber, J. Von Brock, O. Gassmann, and E. Fleisch, Desginging buisness models in the era of Internet of things. International Conferens on Design Scinece in Information Systems, pp 17-31, 2014.

[22] C. Lai, P. Jackson and W. Jiang, Internet of Things Business Models in Ecosystem Context-Cases of Elevator Services, International Journal of Computer and Software Engineering , vol. 3 (135), pp. 1-10, 2018.

[23] I. Ng, and S. Wakenshaw, The Internet-of-Things: Review and Research Directions, International Journal of Research in Marketing, vol.34, pp. 3-21, 2017.

[24] C.-K. Prahalad, and R. Bettis, The Dominant Logic: A New Linkage between Diversity and Performance. Strategic Management Journal , vol. 7 (6), pp. 485-501, 1986.

[25] G.-S. Day, and P.-J. Schoemaker, Avoiding the pitfalls of emerging technologies, California Management Review, vol.42 (2), pp. 8-33, 2000

[26] A. Akram, M. Bergquist, and M. Åkesson, Digital Visions vs. Product Practices: Understanding Tensions in Incumbent Manufacturing Firms. 2014, 47th Hawaii International Conference on System Sciences, pp. 4516-4525 2014.

[27] S.-L. Vargo, and R.-F. Lusch, Evolving to a New Dominant Logic for Marketing, Journal of Marketing , vol. 68 (1), pp.1-17, 2004.

[28] R. Normann, Reframing Business: When the Map Changes the Landscape. New York: John Wiley \& Sons, 2001.

[29] C.-K. Prahalad, and V. Ramaswamy, Co-creation experiences: The next practice in value creation, Journal of Interactive Marketing, vol. 18 (3), pp. 5-14, 2004.

[30] S.-L- Vargo, and R.-L. Lusch, The SAGE handbook of service-dominant logic. London: SAGE Publications, 2019.

[31] R.-F. Lusch, S.-L. Vargo, and A. Gustafsson, Fostering a trans-disciplinary perspectives of service ecosystems, Journal of Business Research, vol. 69 (8), pp.2957-2963, 2016

[32] S.-L. Vargo, and R.-F. Lusch, It's all B2B... and beyond: Toward a systems perspective of the market. Industrial Marketing Management, vol.40 (2), pp.181-187, (2011).

[33] D. Leonard-Barton, Wellsprings of Knowledge. Boston: Harvard Business School Press, 1995.

[34] G. Walsham, Interpretive Case Studies in IS Research: Nature and Method, European Journal of Information Systems , 74-81, 1995.

[35] L.-A. Bettencourt, R.-F Lusch, and S.-L. Vargo, A Service Lens on Value Creation: Marketing's Role in Achieving Strategic Advantage, California Management Review, vol. 57 (1), pp. 44-66, 2014.

[36] S.-L Vargo and R.-F. Lusch, Service-dominant logic 2025. International Journal of Research in Marketing, 34 (1), 46-67, 2016. 